\title{
Evaluation of Some Seeded Dry Date Palm Grown Under Aswan
} Climatic Condition

\section{El-Salhy, A.M. ; R.A. Ibrahim ${ }^{1}$; E.G. Gadalla ${ }^{2}$ and H.K.H. Khalil ${ }^{2}$}

${ }^{1}$ Pomoloty Dept., Fac. Agric., Assiut University, Assiut, Egypt

${ }^{2}$ Central Laboratory for Date Palm Researches and Development, Agric. Res.

Received on: $24 / 5 / 2016$

Accepted for publication on: 15/6/2016

\section{Abstract}

This study was carried out through 2014 and 2015 seasons to evaluate some seeded dry date palm grown in Aswan governorate, Egypt. Their local name, Abd elnaby 1, 2, 3, El-masry 1, 2, Khaled ebn elwalid, Abas gaffer, Radwan and Ali Aamer date palm compared to Sakkoty cv. which is one of the commercial dry cultivar vegetative traits. Yield components and fruit quality as well as numerical evaluation and molecular genetics were investigated.

The obtained results indicated that Ali Aamer date palm type had the highest values of most studied vegetative traits compared to the other studied types. On the other hand, the least values of such traits were recorded of Sakkoty cultivar. El-masry 2 type gave the highest yield components followed by Khaled ebn elwalid and Radwan types, whereas, Abd elnaby 1 gave the least one compared to other studied types. No significant difference was found among Abd elnaby 2, Ali Aamer and Sakkoty cultivar. Khaled ebn elwalid type had the highest values of fruit quality followed by El-masry and Abas gaffer types, whereas, Sakkoty cultivar gave the lowest one compared to the other studied types.

As the numerical evaluation of date palm types, it could be arranged in a descendingly order as follows: Khaled ebn elwalid (86.2), El-masry 2 (84.4), Ali Aamer (81.5), Abas gaffer (80.9), Radwan (77.9), El-masry 1 (77.3), Abd elnaby 3 (76.8), Abd elnaby 2 (72.7), Sakkoty (68.2) and Abd elnaby 1 (67.7 units).

The ISSR data were used to estimate the genetic similarity among the nine date palm strains by using UPGMA computer analysis. The highest similarity index (1.0) was recorded between Abd elnaby 1 and Abas gaffer, while the lowest similarity index was detected (0.0) between El-masry 2 and Ali Aamer. A dendrogram for the genetic relationship among the nine date palm strains was found.

These results revealed that seeded date palm named El-masry 2, Abas gaffer, Khaled ebn elwalid, Ali Amer and Radwan are considered promising to be new strains to obtain a high yield with good fruit quality compared to Sakkoty date palm cultivar.

\section{Keywords: Date palm, Yield, Fruit quality, ISSR, PCR.}

\section{Introduction}

Date palm is one of the ancient domestic fruit trees in the Middle East countries and their fruits play important role in the nutrition patterns of many people as well as a strategic crops in food and biochemical industries (Khayyat et al., 2007). Date palm cultivars are divided into three main groups according to their fruit moisture content, i.e. soft: more than 30\%, semi-dry: from $20-30 \%$ and dry cultivars: less than $20 \%$. Aswan is one of the important areas in Egypt for producing dry cultivars (Hussein et al., 1979). Egypt is considered to be the leading Arab country in producing date (FAO, 2014). The number of fruitful female palms in Egypt are about 12534861 and 
Aswan governorate contributed with 2056929 fruitful female palms (according to Annual Statistical of the Ministry of Agriculture in 2015). Seedling palms represented about $70 \%$ of fruitful female date palms in Aswan governorate. The decrement of superior cultivars number is a big problem. Most of date palm orchards were planted with seeded palms. For successful improvement program of date palm, it could evaluate the unknown seeded date palm trees already grown in big population of seeded date palms. Morphological characteristics of palm trees, fruit physical properties and chemical content of the date fruits are start points for developing promising date palm trees as initial date palm cultivars. Also, it may reveal new and essential informations for better understanding of date fruit that helps to enhance industrialization and propagation of the best date varieties that satisfy producers as well as consumers demands (Rokba et al., 1990; El-Sharabasy et al., 2003; Jaradate and Zaid, 2004; Ismail et al., 2006; Abdalla, 2002 and Gadalla, 2013). There are hundreds of date palm clones that have the potential to become commercial cultivars. Further, many cultivars were transferred from one country to another with new names.

Inter-sample sequence repeats (ISSR) markers have been emerged as an alternative system with reliability and advantages of microsatellites (ISSRs) (Cregan, 1992). The ISSR strategy was therefore performed to access the DNA diversity among crop genotypes (Zehdi et al., 2004). Soliman et al. (2006) identify the genetic polymorphism for semi-dry date palm in Egypt using RAPD and ISSR markers. Abo Rekab et al. (2010) using RAPD and ISSR markers for characterization and construction of genetic linkage maps and the molecular genetic diversity of dry date palm cultivars supported the use of markerassisted selection (MAS) in these cultivars breeding programs.

The genetic improvement of a crop species depends on the ability to select promising plant material. To facilitate the selection process, molecular markers that are associated with important traits can be used as selection tools. The markers can then be used to establish genetic maps, which in turn are important tools for more refined marker assisted selection in breeding programs as well as for indepth genetic and systematic analyses (Soliman et al., 2006).

The aim of the present study was to evaluate the physical and chemical fruit properties of nine domesticated strains besides Sakkoty cv. of Aswan in order to rank them according to their quality. In additions using ISSR markers for characterization and construction of genetic linkage maps and the molecular genetic diversity of these cultivars.

\section{Materials and Methods}

This study was carried out through 2014 and 2015 to evaluate nine strains of date palm grown in Aswan governorate, Egypt comparing with Sakkoty date palm.

These strains included Abd elnaby (1, 2 \& 3); Abdel-Ghafar Elmasry ( 1 \& 2), A. Abas Radwan Esmaeel, Ali Aamer and Saber AbdelAal grown in Alkbabania district, Aswan governorate. 
Table 1. Maximum, low and average temperatures and relative humidity for Aswan governorate during the two experimental seasons.

\begin{tabular}{|c|c|c|c|c|c|c|c|c|c|c|c|c|}
\hline & \multicolumn{9}{|c|}{$\mathbf{2 0 1 4}$} & \multicolumn{6}{c|}{ 2015 } \\
\cline { 2 - 15 } & \multicolumn{3}{|c|}{ Temperature } & \multicolumn{3}{c|}{ Humidity } & \multicolumn{3}{c|}{ Temperature } & \multicolumn{3}{c|}{ Humidity } \\
\cline { 2 - 14 } & High & Low & Avg. & High & Low & Avg. & High & Low & Avg. & High & Low & Avg. \\
\hline Mar & 31.77 & 12.93 & 22.35 & 39.09 & 0.83 & 19.96 & 31.12 & 16.42 & 23.77 & 34.25 & 1.63 & 17.94 \\
\hline Apr & 37.80 & 21.86 & 29.83 & 22.96 & 1.24 & 12.10 & 33.23 & 17.57 & 25.40 & 28.23 & 0.71 & 14.47 \\
\hline May & 39.61 & 23.15 & 31.38 & 24.70 & 0.0 & 12.29 & 39.06 & 24.24 & 31.65 & 23.90 & 2.48 & 13.19 \\
\hline Jun & 41.46 & 26.40 & 33.93 & 25.86 & 0.0 & 12.80 & 40.73 & 25.01 & 32.87 & 28.26 & 2.74 & 15.50 \\
\hline Jul & 42.30 & 28.52 & 35.41 & 27.06 & 0.0 & 13.35 & 41.93 & 26.77 & 34.35 & 25.29 & 3.09 & 14.19 \\
\hline Aug & 42.74 & 28.48 & 35.61 & 25.74 & 2.96 & 14.35 & 44.25 & 29.87 & 37.06 & 27.29 & 4.83 & 16.06 \\
\hline Sept & 39.60 & 25.26 & 32.43 & 32.70 & 3.76 & 18.23 & 41.9 & 27.36 & 34.63 & 32.46 & 1.40 & 16.93 \\
\hline Oct & 34.87 & 21.71 & 28.29 & 40.48 & 4.10 & 22.29 & 38.0 & 23.80 & 30.90 & 46.35 & 7.27 & 26.81 \\
\hline
\end{tabular}

Nine strains of date palms were used. Mother's female palms were propagated by seeds. All palms of each strain received the normal agricultural practice. The palms of each strain under study were near similar in age and growth. The chosen female palms were subjected to the same horticulture practices and hand pollinated using pollen grains of a selected male date palm. In each experimental season, aspects and parameters of the field and laboratory work were as follows:

\section{1- Vegetative parameters:}

The palm trunk girth at one meter above the soil service was measured in meters after harvesting. Four leaves per each palm were randomly detached to calculate, leaf length, number of leaflets and leaflet length and leaflet and leaf area.

Leaflet area $=$ (leaflet length $\mathrm{x}$ maximum width $x$ 0.84), Shabana and Antoun (1980) The number of spines/leaf, spine area on leaf rachis and width of leaf base were calculated.

\section{2- Yield:}

All time of harvesting at tamer stage, number of bunch per palm and weight of all bunches were counted and recorded, then the yield/palm was calculated.

\section{3- Fruit quality:}

After harvesting samples each of 30 fruits per date palm tree for each clones (as a replicate) were sent to the laboratory, the standard physical and chemical fruit properties were studied including the following:

\section{Physical parameters}

Physical characteristics of fruits were carried out during two successive fruiting seasons; the physical properties studied were fruit weight (g), pulp percentage, fruit dimensions $(\mathrm{cm})$ and the fruit shape (L/D) were calculated.

\section{Chemical parameters}

Chemical characteristics such as total soluble solids (TSS) was determined by hand refractometer, total acidity was determined (as g. Malic $\mathrm{acid} / 100 \mathrm{~g}$ pulp), total soluble sugars, reducing sugars, non-reducing sugars and fruit moisture content were determined according to the methods of A.O.A.C. (1985).

General evaluation of the tested strains of date palms cultivars was calculated on the basis of 100 units which were divided among the vegetative growth and fruiting. Hun- 
dred units were shared between the following seedling and Sakkoty cv. 30 units for girth of palm, leaf length and leaf area. 30 units for the average yield per palm and 40 units for fruit weight fresh percentage, total sugars content, soluble solids and moisture content (10 units for each). Each palm that gave the best results in any character was tested and took lower units equal to their quantities.

\section{DNA isolation procedure}

Fresh date palm leaf tissues were collected separately from different cultivars.

The bulked DNA extraction was performed using DNeasy Mini Kit (QIAGEN). Isolation protocol of DNA was as follows:

1- Leaf tissues were ground using liquid nitrogen to a fine powder, then the powder was transferred to an appropriately sized tube.

2- Then, $400 \mu 1$ of buffer AP1 and $4 \mu \mathrm{l}$ of RNase a stock solution $(100 \mathrm{mg} / \mathrm{ml})$ and $5 \mu \mathrm{l}$ proteinase $\mathrm{K}$ were added to a maximum of $100 \mathrm{mg}$ of ground plant tissues and vortexed vigorously.

3- Mixture was incubated for $10 \mathrm{~min}$ at $65^{\circ} \mathrm{C}$ and mixed 2-3 times during incubation by inverting the tube.

4- Then, $130 \mu 1$ of buffer AP2 was added to the lysate, mixed and incubated for $5 \mathrm{~min}$ on ice.

5- Lysate was applied to the Q1A shredder spin column sitting in a $2 \mathrm{ml}$ collection tube and centrifuged for $2 \mathrm{~min}$ at maximum speed (10.000 rpm).

6- Supernatant from step 5 was transferred to a new tube without disturbing the cell-debris pellet. Typically, $450 \mu 1$ of lysate was recovered.
7- Then, 0.5 volume of buffer AP3 and 1 volume of ethanol (96$100 \%$ ) was added to the cleared lysate and mixed by pipetting.

8- Then, $650 \mu 1$ of the mixture from step 7 was applied through DNeasy Mini spin column setting in a $2 \mathrm{ml}$ collection tube. Then, centrifuged for $1 \mathrm{~min}$ at $8000 \mathrm{rpm}$ and the flow-through was then discarded.

9- DNeasy column was then placed in a new $2 \mathrm{ml}$ collection tube. Then, $500 \mu \mathrm{l}$ buffer AW was added onto the DNeasy column and centrifuged for $1 \mathrm{~min}$ at $8000 \mathrm{rpm}$.

10- Then $500 \mu 1$ buffer AW was added to DNeasy column and centrifuged for $2 \mathrm{~min}$ at maximum speed $(10.000 \mathrm{rpm})$ to dry the column membrane.

11- DNeasy column was then transferred to a $1.5 \mathrm{ml}$ microfuge tube and $100 \mu \mathrm{l}$ of preheated $\left(65^{\circ} \mathrm{C}\right)$ buffer AE was pipetted directly onto the DNeasy column membrane. Then, incubated for $5 \mathrm{~min}$ at room temperature and centrifuged for $1 \mathrm{~min}$ at 8000 rpm to elute.

12- Elution was repeated once as described. A new microfuge can be used for first elute. Alternatively, the mcirofuge tube can be reused for the second elution step to combine the elutes.

\section{RAPD-PCR Analysis}

Polymerase chain reaction (PCR) condition stock solutions 5X Tris-borate (TBE), pH 8.0

\begin{tabular}{|c|c|}
\hline Tris-base & $5.40 \mathrm{~g}$ \\
\hline Boric acid & $2.75 \mathrm{~g}$ \\
\hline $500 \mathrm{mM}$ EDTA 8.0 & $0.29 \mathrm{~g}$ \\
\hline $\mathrm{H}_{\mathbf{2}} \mathrm{O}($ d.w) up to & $100.00 \mathrm{ml}$ \\
\hline
\end{tabular}




\section{Ethidium bromide}

1- The stock solution was prepared by dissolving $1 \mathrm{~g}$ of ethidium bromide in $100 \mathrm{ml}$ distilled water.

2- And mixed well with magnetic stirrer.

3- Transferred to a dark bottle and stored at room temperature.

Sample loading dye (5x)

\begin{tabular}{|l|l|}
\hline Na-EDTA, pH $8.0(500 \mathrm{mM})$ & $2.00 \mathrm{ml}$ \\
\hline Glycerol $(100 \%)$ & $5.00 \mathrm{ml}$ \\
\hline Bromophenol blue (2\%) & $0.75 \mathrm{ml}$ \\
\hline $\mathrm{H}_{2} \mathrm{O}$ (d.w.) & $1.50 \mathrm{ml}$ \\
\hline \multicolumn{2}{|c|}{ PCR was performed in $30 \mu \mathrm{lo}-$}
\end{tabular}

lume tubes according to Williams et al. (1990) that contained the following:

\begin{tabular}{|c|c|}
\hline Tris-base & $3.00 \mu \mathrm{l}$ \\
\hline $\mathrm{MgCl}_{2}(25 \mathrm{mM})$ & $3.00 \mu \mathrm{l}$ \\
\hline Buffer $(10 \mathrm{x})$ & $3.00 \mu \mathrm{l}$ \\
\hline Primer $(10 \mathrm{pmol})$ & $2.00 \mu \mathrm{l}$ \\
\hline Taq DNA polymerse $(5 \mathrm{U} / \mu \mathrm{l})$ & $0.20 \mu \mathrm{l}$ \\
\hline Template DNA $(25 \mathrm{ng})$ & $2.00 \mu \mathrm{l}$ \\
\hline $\mathrm{H}_{\mathbf{2}} \mathrm{O}$ (d.w.) & $16.80 \mu \mathrm{l}$ \\
\hline
\end{tabular}

The DNA amplificaitons were perfomed in an automated thermal cycler (model Techno 512) programmed for one cycle at $94^{\circ} \mathrm{C}$ for 4 min followed by 45 cycles of $1 \mathrm{~min}$ at $94^{\circ} \mathrm{C}, 1 \mathrm{~min}$ at $57^{\circ} \mathrm{C}$ and $2 \mathrm{~min}$ at $72^{\circ} \mathrm{C}$, the reaction was finally stored at $72^{\circ} \mathrm{C}$ for $10 \mathrm{~min}$.

\section{Gel preparation procedure}

1- Agarose (1.50 gm) was mixed with $(100 \mathrm{ml}) 1 \mathrm{x}$ TBE buffer and boiled in microwave.

2- Ethidium bromide $(5 \mu \mathrm{l})$ was added to the melted gel after the temperature became $55^{\circ} \mathrm{C}$.

3- The melted gel were poured in the tray of mini-gel apparatus and comb was inserted immediately, then comb was removed when the gel become hardened.

4- The gel was covered by the electrophoretic buffer (1 x TBE).

5- DNA amplified product $(15 \mu \mathrm{l})$ was loaded in each well.

6- DNA ladder (100 bpp) mix was used as a standard DNA with molecular weights of 1500,1000 , 900, 700, 700, 600, 500, 400, 300, 200 and $100 \mathrm{bp}$. The run was performed for about $30 \mathrm{~min}$ at $80 \mathrm{~V}$ in mini submarine gel BioRad.

Inter Sample Sequence Repeat (ISSR-PCR) procedure

PCR reactions were conducted using 5 arbitrary 10-mer primers. Their names and sequences are shown in Table (2). 
Table 2. List of the primer names and their nucleotide sequences used in the study for RAPD procedure.

\begin{tabular}{|c|c|l|c|c|c|}
\hline No. & Name & \multicolumn{1}{|c|}{ Sequence } & No. & Name & \multicolumn{1}{|c|}{ Sequence } \\
\hline 1 & $14 A$ & 5 CTC TCT CTC TCT CTC TTG 3 & 4 & HB-14 & 5' CTC CTC CTC GC 3' \\
\hline 2 & 44B & 5 CTC TCT CTC TCT CTC TGC 3 & 5 & HB-15 & 5' GTG GTG GTG GC 3' \\
\hline 3 & HB-10 & 5 GAG AGA GAG AGA CC 3 & & & \\
\hline
\end{tabular}

The DNA bands generated by each primer were counted and their molecular sizes were compared with those of the DNA markers. The bands scored from DNA profiles generated by each primer were pooled together. Then the presence or absence of each DNA band was treated as a binary character in a data matrix (coded 1 and 0 , respectively) to calculate genetic similarity and to construct dendrogram tree among the studied seven pistachio cultivars. Calculation was achieved using Dice similarity coefficients (Dice, 1945) as implemented in the computer program SPSS-10.

\section{Statistical analysis}

A randomized complete block design was adopted for the present investigation data were statistically analyzed by the standard methods according to Snedecor and Cochran (1980). The New L.S.D. test was used for comparison between means.

\section{Results and Discussion}

The traits of the studied seedling palms and Sakkoty cultivar involved vegetative characteristics, yield and fruit quality:

\section{1- Vegetative characteristics:}

Data in Tables ( $3 \& 4)$ described the vegetative traits of the nine studied seedling female and Sakkoty cultivar. Data declared that there are great variability in vegetative growth of different seedling and Sakkoty palm types during the two studied seasons. Ali Aamer type had the highest values of most studied vegetative traits compared to the other studied types. Ali Aamer date type was superior on palm girth $(1.87 \&$ $1.90 \mathrm{~cm}$ ), leaf length $(4.40 \& 4.27$ $\mathrm{cm})$, width of leaf base $(25 \& 27 \mathrm{~cm})$, zone spine length percentage (22.27 \& 21.31\%), leaflet length (52 \& 55 $\mathrm{cm})$, leaflet area $(126.67 \& 152.46$ $\left.\mathrm{cm}^{2}\right)$ and leaf area $\left(2.66 \& 2.92 \mathrm{~m}^{2}\right)$. On the other hand, the least values of such traits were recorded for Sakkoty palm girth $(1.47 \& 1.50 \mathrm{~cm})$ and leaf length $(3.50 \& 3.57 \mathrm{~cm})$, width of leaf base for Abd elnaby 2 (15 \& 14 $\mathrm{cm})$, Abdel Naby 3 (14 \& $15 \mathrm{~cm}$ ) and Radwan type (14 \& 15), Abd elnaby 3 zone spine length percentage (11.67 $\& 11.43 \%$ ) and leaflet length (36 \& $33 \mathrm{~cm})$ and leaflet area $(52.66 \&$ $\left.72.24 \mathrm{~cm}^{2}\right)$ and leaf area (1.00 \& 1.26 $\mathrm{m}^{2}$ ) for Abd elnaby 1 date type during the two studied seasons. These data indicated that, Abd elnaby 3 and Elmasry 2 date palm type gave the followed highest values of palm girth and leaf length as well as Khaled ebn elwalid palm had the followed highest values of leaflet length, leaflet area and leaf area. The intermediate values of these traits were found on other studied date palm type during both studied seasons. These data indicated that Ali Amer, Abdel Naby 3 and El-masry 2 palms type were the biggest palms, whereas, the Sakkoty cultivar was the smallest ones in comparison to the other studied palm type, in addition to the least area related to the leaflet number and its area. 
Table 3. Vegetative characteristics of some seeded dry palms and Sakkoty cultivar grown under Aswan condition during 2014 season.

\begin{tabular}{|c|c|c|c|c|c|c|c|c|c|c|}
\hline \multicolumn{2}{|c|}{ Character } & 氞 & 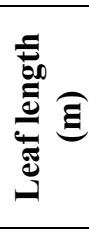 & 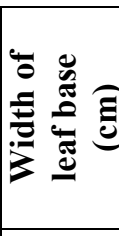 & $\begin{array}{l}\stackrel{\mathscr{E}}{0} \\
\frac{\pi}{0} \\
\dot{0} \\
\dot{z}\end{array}$ & 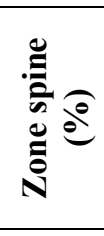 & 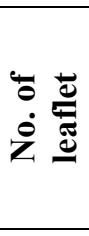 & 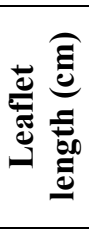 & 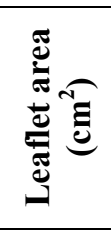 & 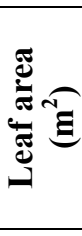 \\
\hline 1 & Abd elnaby 1 & 1.55 & 4.18 & 14 & 22 & 14.35 & 190 & 38 & 52.66 & 1.00 \\
\hline 2 & Abd elnaby 2 & 1.60 & 4.10 & 15 & 16 & 14.88 & 212 & 42 & 74.08 & 1.57 \\
\hline 3 & Abd elnaby 3 & 1.70 & 3.60 & 14 & 18 & 11.67 & 200 & 36 & 93.74 & 1.87 \\
\hline 4 & El-masry 1 & 1.50 & 4.43 & 22 & 26 & 16.25 & 210 & 39 & 85.17 & 1.78 \\
\hline 5 & Kh. ebn elwalid & 1.65 & 4.14 & 22 & 34 & 18.12 & 236 & 46 & 112.06 & 2.64 \\
\hline 6 & Abas gaffer & 1.60 & 4.10 & 18 & 30 & 16.58 & 242 & 39 & 95.0 & 2.24 \\
\hline 7 & El-masry 2 & 1.66 & 4.40 & 25 & 20 & 13.64 & 220 & 40 & 87.36 & 1.92 \\
\hline 8 & Radwan & 1.48 & 3.70 & 14 & 22 & 18.92 & 190 & 42 & 95.25 & 1.80 \\
\hline 9 & Ali Aamer & 1.87 & 4.40 & 25 & 34 & 22.27 & 206 & 52 & 126.67 & 2.60 \\
\hline 10 & Sakkoty cv. & 1.47 & 3.50 & 22 & 26 & 18.29 & 198 & 42 & 74.08 & 1.46 \\
\hline
\end{tabular}

Table 4. Vegetative characteristics of some seeded dry palms and Sakkoty cultivar grown under Aswan condition during 2015 season.

\begin{tabular}{|c|c|c|c|c|c|c|c|c|c|c|}
\hline $\begin{array}{l}\text { See } \\
\text { loca }\end{array}$ & Cha & 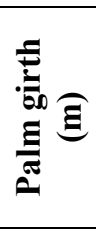 & 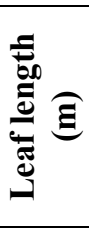 & 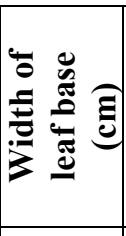 & $\begin{array}{l}\frac{\mathscr{E}}{2} \\
\frac{0}{0} \\
\dot{0} \\
\dot{0}\end{array}$ & 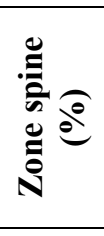 & $\begin{array}{l}\dot{0} \\
\dot{\theta} \\
\dot{z}\end{array}$ & 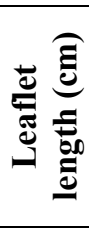 & 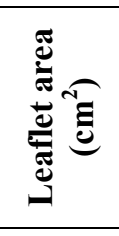 & 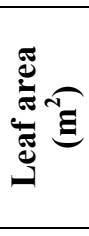 \\
\hline 1 & Abd elnaby 1 & 1.60 & 4.21 & 16 & 30 & 14.49 & 174 & 43 & 72.24 & 1.26 \\
\hline 2 & Abd elnaby 2 & 1.60 & 4.00 & 14 & 16 & 15.00 & 222 & 40 & 67.60 & 1.50 \\
\hline 3 & Abd elnaby 3 & 1.75 & 3.50 & 15 & 16 & 11.43 & 190 & 33 & 83.16 & 1.58 \\
\hline 4 & El-masry 1 & 1.60 & 4.21 & 23 & 20 & 15.68 & 204 & 40 & 94.08 & 1.91 \\
\hline 5 & Kh. ebn elwalid & 1.70 & 4.00 & 20 & 36 & 17.50 & 240 & 43 & 111.97 & 2.68 \\
\hline 6 & Abas gaffer & 1.60 & 3.94 & 20 & 22 & 15.74 & 224 & 40 & 100.80 & 2.25 \\
\hline 7 & El-masry 2 & 1.75 & 4.26 & 26 & 22 & 12.70 & 240 & 40 & 84.00 & 2.02 \\
\hline 8 & Radwan & 1.50 & 3.60 & 15 & 18 & 16.67 & 200 & 45 & 94.50 & 1.89 \\
\hline 9 & Ali Aamer & 1.90 & 4.27 & 27 & 32 & 21.31 & 192 & 55 & 152.46 & 2.92 \\
\hline 10 & Sakkoty cv. & 1.50 & 3.47 & 23 & 28 & 18.73 & 196 & 45 & 86.94 & 1.70 \\
\hline
\end{tabular}

\section{2- Yield components:}

The results obtained from the evaluation of seedling female palm types and Sakkoty palm cultivar during 2014 and 2015 seasons were represented in Tables $(5 \& 6)$. The data showed significant variation in bunches number per palm, their weight and yield/palm. Bunches number ranged from 10 to 25 bunch/palm in the different palm types. Bunch weight ranged from 4.0 
to $14.0 \mathrm{~kg}$ and consequently the yield/palm attained 54.0 to 140 $\mathrm{kg} / \mathrm{palm}$. The highest bunch number $(20 \& 18)$ and ( $25 \& 24$ bunch) were recorded on Abd elnaby 2 and Abd elnaby 3 date seedling, followed in descending order by Abas gaffer seedling $(15 \& 14)$ during the two studied seasons, respectively. Elmasry 2 date seedling gave the heaviest bunch $(14.0 \& 13.7 \mathrm{~kg})$ followed in descending order by Khaled ebn elwalid date seedling (13.0 \& $11.0 \mathrm{~kg})$ and El-masry $1(11.8$ \& 9.5 $\mathrm{kg}$ ) during the two studied seasons, respectively. Also, El-masry 2 date seedling gave the heaviest yield/palm (140 \& $136 \mathrm{~kg} / \mathrm{palm})$, followed by Abas gaffer date seedling $(135 \& 110$ $\mathrm{kg} / \mathrm{palm}$ ) and Khaled ebn elwalid $(130 \& 130 \mathrm{~kg} / \mathrm{palm})$ during the two studied seasons, respectively. On the other hand, El-masry 2 and Khaled ebn elwalid seedling gave the least bunch number $(10 \& 10 \mathrm{bunch} / \mathrm{palm})$, as well as Abd elnaby 3 gave the lightest bunch weight $(4.0 \& 4.7 \mathrm{~kg})$ and Abd elnaby 1 gave the least yield $/$ palm $(100 \& 54 \mathrm{~kg} / \mathrm{palm})$ during the two studied seasons, respectively. Other studied seedling dates gave intermediate values of bunch number, bunch weight and yield/palm. It is noticed that there are unsignificant differences among bunch number emergence per palm of El-masry $2(10 \& 10)$ and Khaled ebn elwalid (10 \& 10) date seedling as well as Radwan (13 \& 13) and Ali Amer (13 \& 13 bunch). Also, non significant differences were found among bunch weight of Radwan (8.8 $\mathrm{kg})$ and Sakkoty $(8.6 \mathrm{~kg})$ during the first season, Abd elnaby 1 (4.5), Abd elnaby 2 (4.6) and Abd elnaby 3 (4.7 $\mathrm{kg}$ ) during the second season. No significant difference on yield/palm among Abd elnaby 1 (100), Abd elnaby 3 seedling (102) and Sakkoty cultivar $(103.5 \mathrm{~kg})$ in the first season, as well as El-masry 1 seedling (95 $\mathrm{kg})$ and Sakkoty cultivar $(98.0 \mathrm{~kg})$ in the second season.

\section{3- Fruit quality:}

Data of various fruit characteristics of some seedling date palm and Sakkoty cultivar grown under Aswan condition during 2014 and 2015 seasons are presented in Tables (5 to 8). Data indicated that most studied seedling date palms were significant varied in fruit quality. The fruit weight, fruit length, flesh percentage and fruit shape were ranged from (6.70 to $24.12 \& 6.77$ to $25.43 \mathrm{~g}$ ), (4.50 to $7.60 \& 4.50$ to 7.60$),(86.18$ to $96.46 \& 87.66$ to $96.29 \%$ ) and (1.80 to $3.15 \& 1.45$ to 3.30 ) during the two studied seasons, respectively. Khaled ebn elwalid fruits was the heaviest $(24.12 \& 25.43 \mathrm{~g})$, longest $(7.60 \& 7.60 \mathrm{~cm})$, highest flesh percentage (96.46 \& 96.29\%) and highest fruit shape index (3.51 \& 3.30) among the tested seedling dates and Sakkoty cultivar in both the studied seasons, respectively. On the other hand, Sakkoty fruits was the lightest $(6.70 \& 6.77 \mathrm{~g})$ and least flesh percentage ( $86.18 \& 87.66 \%$ ), as well as Ali Aamer fruits was shortest $(4.50$ \& $4.50 \mathrm{~cm}$ ) and least fruit shape index $(1.80 \& 1.45)$ compared to the studied seedling date fruits during the two studied seasons, respectively. 
Table 5. Yield components and some physical characteristics of fruit of some seeded dry palms and Sakkoty cultivar during 2014 season.

\begin{tabular}{|c|c|c|c|c|c|c|c|c|c|}
\hline \multicolumn{2}{|c|}{ Character } & \multirow[t]{2}{*}{ 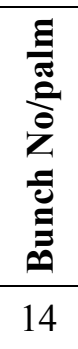 } & \multirow[t]{2}{*}{ 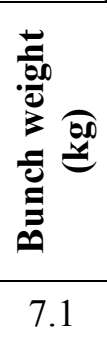 } & \multirow[t]{2}{*}{ 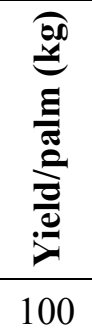 } & \multirow[t]{2}{*}{ 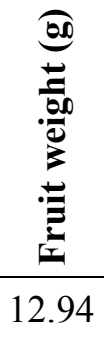 } & \multirow[t]{2}{*}{ 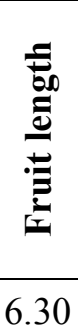 } & \multirow[t]{2}{*}{ 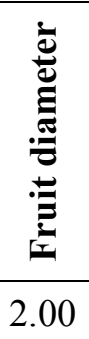 } & \multirow[t]{2}{*}{ 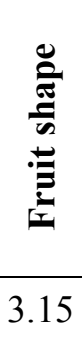 } & \multirow{2}{*}{ 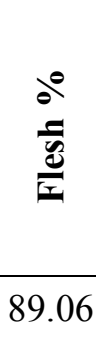 } \\
\hline 1 & Abd elnaby 1 & & & & & & & & \\
\hline 2 & Abd elnaby 2 & 20 & 6.5 & 130 & 7.48 & 4.7 & 1.70 & 2.76 & 86.48 \\
\hline 3 & Abd elnaby 3 & 25 & 4.0 & 102 & 12.59 & 5.80 & 2.17 & 2.68 & 87.29 \\
\hline 4 & El-masry 1 & 11 & 11.8 & 130 & 9.04 & 4.50 & 2.0 & 2.26 & 87.37 \\
\hline 5 & Kh. Ebn elwalid & 10 & 13.0 & 130 & 24.12 & 7.60 & 2.27 & 3.51 & 96.46 \\
\hline 6 & Abas gaffer & 15 & 9.0 & 135 & 13.28 & 5.40 & 2.0 & 2.71 & 89.56 \\
\hline 7 & El-masry 2 & 10 & 14.0 & 140 & 10.68 & 5.20 & 2.13 & 2.57 & 92.45 \\
\hline 8 & Radwan & 13 & 8.8 & 115 & 11.59 & 5.20 & 2.00 & 2.60 & 90.95 \\
\hline 9 & Ali Aamer & 13 & 8.4 & 110 & 10.83 & 4.50 & 2.50 & 1.80 & 88.51 \\
\hline 10 & Sakkoty cv. & 12 & 8.6 & 103.5 & 6.70 & 4.92 & 1.99 & 2.48 & 86.18 \\
\hline & L.S.D. & 0.73 & 0.25 & 4.37 & 0.71 & 0.18 & 0.11 & 0.17 & 0.88 \\
\hline
\end{tabular}

Table 6. Yield components and some physical characteristics of fruit of some seeded dry palms and Sakkoty cultivar during 2015 season.

\begin{tabular}{|c|c|c|c|c|c|c|c|c|c|}
\hline \multicolumn{2}{|c|}{$\begin{array}{l}\text { Seedling } \\
\text { local name }\end{array}$} & \multirow{2}{*}{ 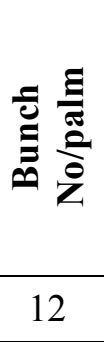 } & \multirow{2}{*}{ 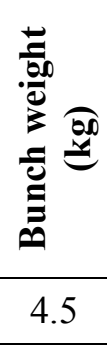 } & \multirow{2}{*}{ 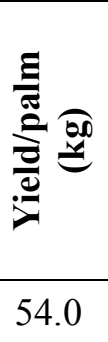 } & \multirow{2}{*}{ 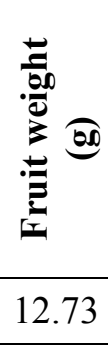 } & \multirow{2}{*}{ 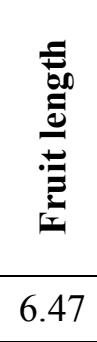 } & \multirow{2}{*}{ 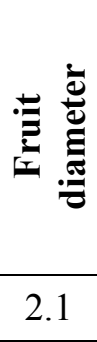 } & \multirow{2}{*}{ 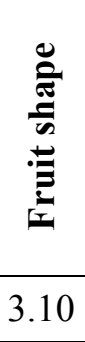 } & \multirow{2}{*}{ 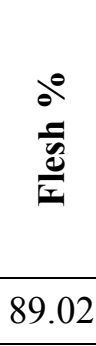 } \\
\hline 1 & Abd elnaby 1 & & & & & & & & \\
\hline 2 & Abd elnaby 2 & 18 & 4.6 & 85.0 & 12.81 & 5.50 & 1.90 & 2.90 & 90.54 \\
\hline 3 & Abd elnaby 3 & 24 & 4.7 & 107 & 13.27 & 6.20 & 2.20 & 2.82 & 90.92 \\
\hline 4 & El-masry 1 & 11 & 9.5 & 95 & 13.56 & 5.30 & 2.20 & 2.41 & 89.25 \\
\hline 5 & Kh. Ebn elwalid & 10 & 11.0 & 110.3 & 25.43 & 7.60 & 2.30 & 3.30 & 96.29 \\
\hline 6 & Abas gaffer & 14 & 7.85 & 110 & 13.52 & 5.70 & 2.17 & 2.63 & 91.56 \\
\hline 7 & El-masry 2 & 10 & 13.70 & 136 & 12.21 & 5.40 & 2.30 & 2.35 & 88.77 \\
\hline 8 & Radwan & 13 & 10.0 & 130 & 11.77 & 5.90 & 2.00 & 2.95 & 89.82 \\
\hline 9 & Ali Aamer & 13 & 8.30 & 100 & 10.80 & 4.50 & 3.10 & 1.45 & 90.31 \\
\hline 10 & Sakkoty cv. & 10 & 9.75 & 98.0 & 6.77 & 5.02 & 2.07 & 2.43 & 87.66 \\
\hline & L.S.D. & 0.57 & 0.31 & 3.72 & 0.95 & 0.17 & 0.10 & 0.15 & 0.93 \\
\hline
\end{tabular}


Table 7. Chemical constituents of fruit pulp of some seeded dry palms and Sakkoty cultivar during 2014 season.

\begin{tabular}{|c|l|c|c|c|c|c|c|}
\hline \multicolumn{2}{|l|}{$\begin{array}{l}\text { Seedling } \\
\text { local name }\end{array}$} & $\begin{array}{c}\text { Moisture } \\
\text { content } \\
\%\end{array}$ & $\begin{array}{c}\text { Acidity } \\
\%\end{array}$ & TSS & $\begin{array}{c}\text { Total su- } \\
\text { gars }\end{array}$ & $\begin{array}{c}\text { Reducing } \\
\text { sugars }\end{array}$ & $\begin{array}{c}\text { Non } \\
\text { reducing } \\
\text { sugars }\end{array}$ \\
\hline 1 & Abd elnaby 1 & 17.25 & 0.253 & 66.60 & 53.92 & 33.41 & 20.51 \\
\hline 2 & Abd elnaby 2 & 17.19 & 0.165 & 67.30 & 53.92 & 32.90 & 21.02 \\
\hline 3 & Abd elnaby 3 & 15.88 & 0.134 & 72.00 & 56.00 & 32.77 & 23.22 \\
\hline 4 & El-masry 1 & 14.30 & 0.130 & 72.00 & 57.60 & 35.18 & 22.42 \\
\hline 5 & Kh. Ebn elwalid & 16.99 & 0.176 & 66.80 & 53.65 & 33.10 & 20.55 \\
\hline 6 & Abas gaffer & 13.57 & 0.172 & 74.00 & 58.12 & 35.57 & 22.55 \\
\hline 7 & El-masry 2 & 12.84 & 0.168 & 75.00 & 57.81 & 35.35 & 22.55 \\
\hline 8 & Radwan & 13.60 & 0.136 & 76.00 & 58.85 & 35.72 & 23.13 \\
\hline 9 & Ali Aamer & 14.39 & 0.139 & 76.00 & 58.25 & 34.85 & 23.40 \\
\hline 10 & Sakkoty cv. & 17.80 & 0.125 & 65.40 & 52.00 & 32.00 & 20.00 \\
\hline \multicolumn{2}{|c|}{ L.S.D. } & 0.85 & 0.012 & 2.18 & 0.51 & 0.67 & 0.46 \\
\hline
\end{tabular}

Table 8. Chemical constituents of fruit pulp of some seeded dry palms and Sakkoty cultivar during 2015 season.

\begin{tabular}{|c|l|c|c|c|c|c|c|}
\hline \multicolumn{2}{|c|}{$\begin{array}{l}\text { Seedling Character } \\
\text { local name }\end{array}$} & $\begin{array}{c}\text { Moisture } \\
\text { content \% }\end{array}$ & $\begin{array}{c}\text { Acidity } \\
\%\end{array}$ & TSS & $\begin{array}{c}\text { Total su- } \\
\text { gars }\end{array}$ & $\begin{array}{c}\text { Reducing } \\
\text { sugars }\end{array}$ & $\begin{array}{c}\text { Non } \\
\text { reducing } \\
\text { sugars }\end{array}$ \\
\hline 1 & Abd elnaby 1 & 17.31 & 0.262 & 68.0 & 55.41 & 32.67 & 22.74 \\
\hline 2 & Abd elnaby 2 & 17.22 & 0.154 & 68.0 & 53.72 & 32.60 & 21.12 \\
\hline 3 & Abd elnaby 3 & 16.10 & 0.123 & 70.0 & 54.32 & 32.22 & 22.10 \\
\hline 4 & El-masry 1 & 15.90 & 0.136 & 70.0 & 56.29 & 34.72 & 21.57 \\
\hline 5 & Kh. Ebn elwalid & 17.30 & 0.176 & 69.0 & 54.40 & 32.64 & 21.76 \\
\hline 6 & Abas gaffer & 14.70 & 0.172 & 72.8 & 56.84 & 34.38 & 22.46 \\
\hline 7 & El-masry 2 & 13.30 & 0.165 & 74.0 & 55.71 & 32.18 & 23.53 \\
\hline 8 & Radwan & 13.60 & 0.125 & 74.6 & 58.00 & 35.11 & 22.89 \\
\hline 9 & Ali Aamer & 15.30 & 0.143 & 73.8 & 57.86 & 34.92 & 22.94 \\
\hline 10 & Sakkoty cv. & 17.70 & 0.140 & 66.6 & 52.50 & 31.50 & 21.00 \\
\hline \multicolumn{2}{|c|}{ L.S.D. } & 0.68 & 0.011 & 2.56 & 0.43 & 0.50 & 0.44 \\
\hline
\end{tabular}

Other studied seedling date fruits recorded intermediate reading for these studied fruit traits. It is noticed that no significant differences in fruit weight among Abd elnaby 1 (12.94 \& 12.73), Abd elnaby 3 (12.59
\& $13.27 \mathrm{~g})$ and Abas gaffer $(13.28 \&$ $13.52 \mathrm{~g})$, as well as El-masry 2 (10.68 \& 12.21), Radwan (11.59 \& $11.77 \mathrm{~g}$ ) and Ali Aamer fruits $(10.83 \& 10.80$ g). 
In respect to the chemical fruit characteristics, data in the previous tables indicated that most studied date palm fruits were significantly varied in chemical fruit characteristics. Data showed that moisture content, total soluble solids, total sugars and reducing sugars were ranged from $(12.84$ to $17.80 \& 13.30$ to $17.70 \%),(65.4$ to $76.0 \& 66.6$ to 74.6$)$ and (32.0 to $35.72 \& 31.50$ to $35.11 \%$ ) in both the studied seasons, respectively. Sakkoty fruits had the highest moisture content and lowest values of other chemical characteristics compared to the studied seedling date palm fruits. On the other hand, Radwan seedling date fruits had the highest total soluble solids (TSS) $(76.0 \& 74.6 \%)$ and total sugars content $(58.85 \& 58.00 \%)$ and reducing sugars $(34.85 \& 35.11 \%)$. In contrast, El-masry 2 fruits had the lowest moisture content (12.84 \& $13.30 \%$ ) during the two studied seasons, respectively. Intermediate values of all the studied chemical constituents were recorded for the other studied seedling date fruits. Data declared that no significant difference was found in fruit moisture content among Abd elnaby $1 \quad(17.25$ \& 17.31), Abd elnaby 2 (17.19 \& $17.22 \%)$, Khaled ebn elwalid (16.79 \& $17.30 \%)$ and Sakkoty fruits (17.80 \& $17.70 \%$ ), as well as El-masry 2 (12.84 \& 13.30\%) and Radwan $(13.60 \& 13.60 \%)$ during the two studied seasons, respectively. No significant differences in TSS were found between Radwan (76.0 \& 74.6\%), Ali Aamer (76.0 \& 73.8\%), El-masry $2(75.0 \& 74.0 \%)$ and Abas gaffer fruits $(74.0 \& 72.8 \%)$, as well as between Sakkoty (65.4 \& 66.6), Abd elnaby 1 (66.6 \& 68.0\%), Abd elnaby $2(67.3 \& 68.0 \%)$, Khaled ebn elwalid (66.8 \& 69.0\%) during the two studied seasons, respectively. Such results indicated that Abas gaffer, El-masry 2, Radwan and Ali Aamer seedling date palms had the best chemical fruit quality compared to Sakkoty cultivar and other investigated seedling date palm.

Such results emphasized the fact not vegetative and fruiting traits depend on cultivar. The differences between cultivars or seedling types of date palm may be due to either cytological differences between them or to the genotypes that are transmitted via seeds. These results are in line with those obtained by Rokba et al., 1990; Abdalla, 2002; El-Sharabasy et al., 2003; Jaradate and Zaid, 2004; Ismail et al., 2006; Ibrahim, 2008; Abdalla, 2012 and Gadalla, 2013. Who mentioned that there was a wide and great variation on vegetative growth and fruiting of most date palm strains or cultivars.

\section{General evaluation of the studied date palm strains:}

The numerical evaluation of date palm strains (Table 9) showed that, Khaled ebn elwalid and Elmasry 2 recorded the highest units according to the general evaluation, as it attained the uppermost score units $(86.2 \& 84.4)$ followed by Ali Aamer strain which occupied the third ranked (81.5), followed by Abas gaffer strain (80.9). These strains have excelled of Sakkoty cv. which is one of the best cultivar in Aswan. 
Table 9. General evaluation of the studied seedling type and Sakkoty cultivar grown under Aswan condition as average of the two studied seasons.

\begin{tabular}{|c|c|c|c|c|c|c|c|c|c|c|c|c|c|c|c|}
\hline \multicolumn{2}{|c|}{ Characters } & \multicolumn{4}{|c|}{ Vegetative growth } & \multicolumn{4}{|c|}{ Yield components } & \multicolumn{5}{|c|}{ Dates quality } & \multirow[b]{2}{*}{$\begin{array}{c}\text { G. } \\
\text { tota }\end{array}$} \\
\hline & edling type & $\begin{array}{c}\text { Girth } \\
\text { (m) }\end{array}$ & $\begin{array}{c}\text { Leaf } \\
\text { length } \\
(\mathrm{m})\end{array}$ & $\begin{array}{l}\text { Leaf } \\
\text { area } \\
\left(\mathrm{m}^{2}\right)\end{array}$ & Total & $\begin{array}{c}\text { Bunch } \\
\text { No. }\end{array}$ & $\begin{array}{c}\text { Bunch } \\
\text { weight } \\
\text { (kg) }\end{array}$ & $\begin{array}{c}\text { Yield/ } \\
\text { palm } \\
\text { (kg) }\end{array}$ & Tota & $\begin{array}{c}\text { Fruit } \\
\text { weight } \\
\text { (g) }\end{array}$ & $\begin{array}{c}\text { Flesh } \\
(\%)\end{array}$ & $\begin{array}{c}\text { Moisture } \\
\text { content } \\
(\%)\end{array}$ & TSS & Total & \\
\hline & ore units & 10 & 10 & 10 & 30.0 & 10 & 10 & 10 & 30 & 10 & 10 & 10 & 10 & 40 & 100 \\
\hline 1 & Abd elnaby 1 & 8.3 & 9.68 & 4.1 & 22.08 & 5.3 & 4.3 & 5.5 & 15.1 & 5.0 & 9.3 & 7.3 & 8.9 & 30.5 & 67.7 \\
\hline 2 & Abd elnaby 2 & 8.5 & & 5.5 & 23.34 & 7.8 & & 78 & 19.7 & & 9.2 & & 9.2 & 29.7 & 72.7 \\
\hline 3 & Abd elnaby 3 & 9.1 & 8.2 & 6.2 & 23.5 & 10.0 & 3.2 & 7.6 & 20.8 & 5.5 & 9.3 & 8 & 9.4 & 32.5 & 76.8 \\
\hline 41 & El-masry 1 & 8.2 & 9.97 & 6.7 & 24.87 & 4.5 & 7.9 & 8.1 & 20.5 & 4.5 & 9.2 & 8.8 & 9.4 & 31.9 & 77.3 \\
\hline 5 & Kh. Ebn elwalid & 8.9 & & 9.6 & 27.9 & 4.1 & & & 21.6 & 10.0 & 10 & & 9.0 & 36.7 & 86.2 \\
\hline 6 & Abas gaffer & 8.5 & & 8.2 & 25.98 & 5.9 & & 8.8 & 20.9 & 5. & 9.4 & & 9.8 & 34.0 & 80.9 \\
\hline 7 & El-masry 2 & 9.0 & 9.98 & 7.1 & 26.1 & 4.1 & 10 & 10 & 24.1 & 4.6 & 9.4 & 10.0 & 9.9 & 33.9 & 84.4 \\
\hline 81 & Radwan & 7.9 & 8.4 & 6.7 & 23.02 & 5.3 & 6.9 & 8.8 & 21.0 & 4.7 & 9.4 & 9.8 & 10.0 & 33.9 & 77.9 \\
\hline 9 & Ali Aamer & 10 & 10 & 10 & 30.0 & 5.3 & 6.2 & 7.6 & 19.1 & 4.3 & 9.2 & 9.0 & 9.9 & 32.4 & 81.5 \\
\hline 10 & Sakkoty cv. & 7.9 & 8.0 & 5.7 & 21.63 & 4.5 & 6.8 & 7.3 & 18.6 & 2.7 & 9.0 & 7.6 & 8.7 & 28.0 & 68.2 \\
\hline
\end{tabular}

The numerical evaluation of these strains (average two seasons) showed that; they were in a descending order as follows: Khaled ebn elwalid (86.2), El-masry 2 (84.4), Ali Aamer (81.5), Abas gaffer (80.9), Radwan (77.9), El-masry 1 (77.3), Abd elnaby 3 (76.8), Abd elnaby 2 (72.7), Sakkoty (68.2) and Abd elnaby 1 (67.7 units) on total units including vegetative growth and fruiting.

The total score (40 units) for fruit quality of date palm (fruit weight, flesh percentage, TSS and moisture content) was significantly varied according to some date palm seedling. All strains gave the highest values compared to Sakkoty cultivar. The tested strains could be arranged descendingly based on total score (40) for fruit quality as follows:

Khaled ebn elwalid (36.7), Abas gaffer (34.0), El-masry 2 (33.9), Radwan (33.9), Abdel Naby 3 (32.5), Ali Aamer (32.4), El-masry 1 (31.9), Abdel Naby 1 (30.5), Abdel Naby 2 (29.7) and Sakkoty (28.0).

Such results showed clearly that palm named Khaled ebn elwalid, Elmasry 2, Ali Aamer and Abas gaffer are considered promising to be new strains which are obtained from seeded palms grown under Aswan conditions.

In general, the dry date palm strains under study were widely different in their growth, yield and phy- siochemical properties. Variations among these strains could be mainly due to their genetically and adaptability differences. Hence these results are important from economic and horticultural point of view. The best one must be selected for vegetative propagation and planting.

\section{Molecular markers: Identification of ISSR-PCR mark-} ers:

ISSR is a class of molecular markers based on inter-tandem repeats of short DNA sequences. These inter repeats are highly polymorphic, even among closely related genotypes, due to the lack of functional constraints in these non-functioning regions. Similarly, a high level of polymorphism was generated utilizing the two ISSR-PCR primers (Figure 1 and Table 10). A total number of 58 ISSR bands were obtained. Of these, 19 bands were monomorphic $(32.75 \%)$ and 38 were polymorphic $(67.24 \%)$. The highest number of amplicons was generated.

Polymorphism levels differed from one primer to the other. Primers 14A (85.71\%), HB-12 (70.58\%) and HB-08 $(66.67 \%)$ exhibited high polymorphism. On the other hand, primers HB-15 (63.63\%) exhibited moderate levels, whereas, primer 44B $(28.57 \%)$ exhibited low polymorphism. 


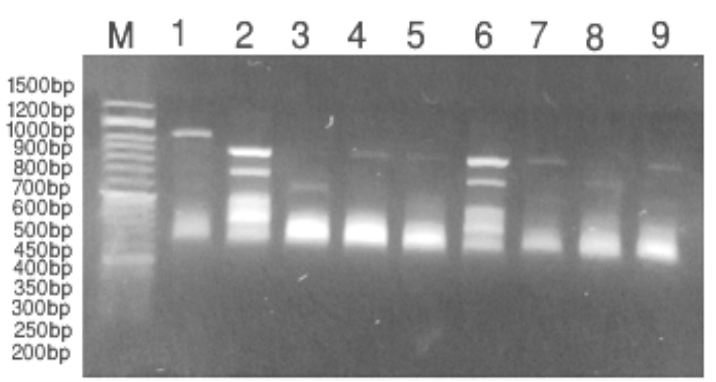

$14 \mathrm{~A}$

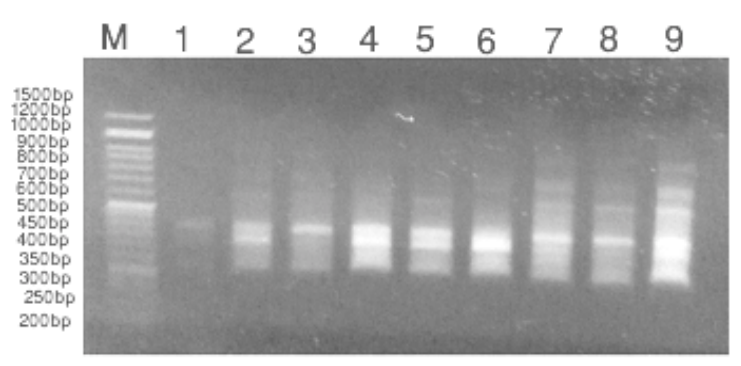

HB-08

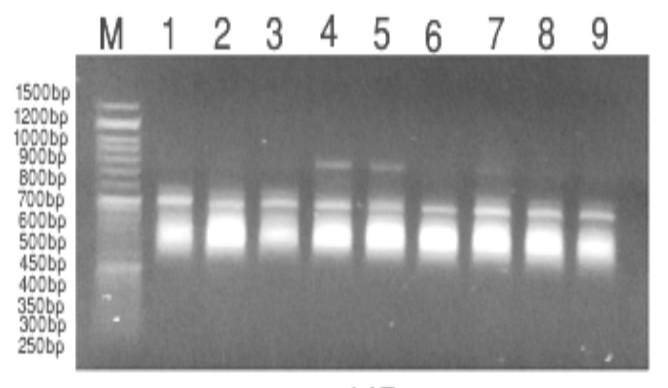

$44 \mathrm{~B}$

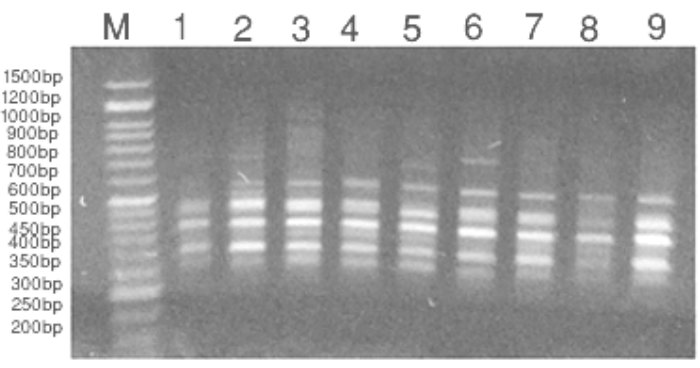

HB-12

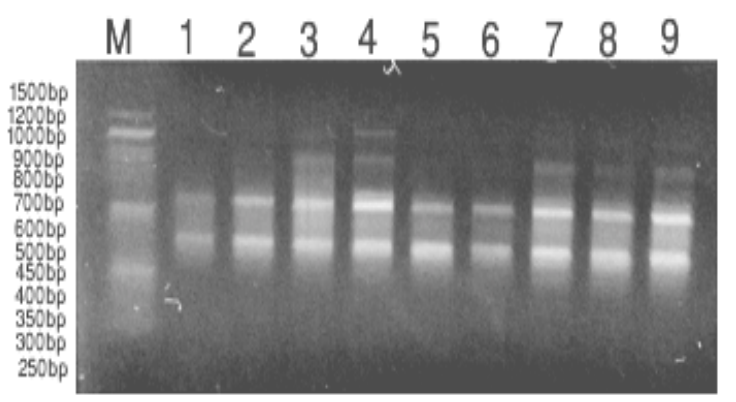

HB-15

Figure 1: ISSR profiles of the 9 dry date palm strains amplified with five primers for each analysis.

\section{1- Primer (14A):}

The results of ISSR analysis yielded by primer (14A) are illustrated in Table (10). Primer (14A) reacted with all cultivars. The Molecular Weight (M.W.) of the PCR products generated by this primer ranged from (330) to (995) bp. Also, the total number of bands was fourty six resulted, the number of total bands varied between cultivars. The lowest number was 3 with El-masry 1 date type while the highest number was 7 with both Abdel Naby 2 and Abas gaffer types date.

\section{2- Primer (44B):}

The results of ISSR analysis obtained by primer (44B) are presented in Table (10). Results showed that primer (44B) reacted with all cultivars. The M.W. of the DNA fragments generated by this primer ranged from (286) to (711) bp. The total number of bands was fifty four resulted. The number of bands varied between cultivars. The lowest number of bands was 5 with Khaled ebn elwalid date type and the highest number was 7 with El-masry 2 date type.

\section{3- Primer (HB-08):}


Table (10) showed the results ISSR analysis obtained by primer (HB-08). Primer (HB-08) reacted with all cultivars. The M.W. of the PCR products generated by the primer ranged from (248) to (793) bp. The primer revealed sixty two reproducible bands with different M.W which varied between cultivars. The lowest number of bands 3 was found with Abd elnaby 1 date type, while the highest number 9 was found with El-masry 2, Radwan and Ali Aamer date types.

\section{4- Primer (HB-12):}

Table (10) gave the results of ISSR analysis obtained by primer (HB-12). Primer (HB-12) reacted with all cultivars, producing PCR products ranged from (245) to (961) bp.
Seventy four distinguishable bands with different M.W. were resulted and varied between cultivars. The lowest number of bands was 6 with Radwan date type and the highest number was (11) with Abd elnaby 3 date type.

\section{5- Primer (HB-15):}

The results of ISSR analysis products obtained by primer (HB-15) are illustrated in Table (10). Primer (HB-15) reacted with all cultivars. A total of 61 distinguishable bands with different M.W. ranged from (278) to (1118) bp were produced.

The types with Khaled ebn elwalid and Abas gaffer showed the lowest number of bands (4 bands), while with Abd elnaby 3, El-masry 2, Radwan and Ali Aamer had the highest number ( 9 bands).

Table 10. Number of amplified fragments markers of nine seeded dry date palm $14 \mathrm{~A}$ with five primers for each analysis.

\begin{tabular}{|c|c|c|c|c|c|c|c|c|c|}
\hline $\mathbf{M W}$ & $\begin{array}{c}\text { Abd } \\
\text { elnaby } \\
\mathbf{1}\end{array}$ & $\begin{array}{c}\text { Abd } \\
\text { elnaby } \\
\mathbf{2}\end{array}$ & $\begin{array}{c}\text { Abd } \\
\text { elnaby } \\
\mathbf{3}\end{array}$ & $\begin{array}{c}\text { El- } \\
\text { masry } \\
\mathbf{1}\end{array}$ & $\begin{array}{c}\text { Kh. } \\
\text { Ebn } \\
\text { elwald }\end{array}$ & $\begin{array}{c}\text { Abas } \\
\text { gaffer }\end{array}$ & $\begin{array}{c}\text { El- } \\
\text { masry } \\
\mathbf{2}\end{array}$ & Radwan & $\begin{array}{c}\text { Ali Aa- } \\
\text { mer }\end{array}$ \\
\hline $\mathbf{9 9 5}$ & 1 & 0 & 0 & 0 & 0 & 0 & 0 & 0 & 0 \\
\hline $\mathbf{7 9 0}$ & 0 & 1 & 0 & 1 & 1 & 1 & 1 & 0 & 1 \\
\hline $\mathbf{7 4 6}$ & 0 & 1 & 0 & 0 & 0 & 1 & 0 & 0 & 0 \\
\hline $\mathbf{7 3 6}$ & 0 & 0 & 0 & 0 & 0 & 0 & 0 & 0 & 0 \\
\hline $\mathbf{6 6 7}$ & 1 & 0 & 0 & 0 & 0 & 0 & 0 & 0 & 0 \\
\hline $\mathbf{6 1 9}$ & 1 & 0 & 0 & 0 & 0 & 0 & 0 & 1 & 0 \\
\hline $\mathbf{6 0 4}$ & 0 & 1 & 0 & 0 & 0 & 1 & 0 & 0 & 0 \\
\hline $\mathbf{5 8 8}$ & 0 & 0 & 1 & 0 & 0 & 0 & 0 & 0 & 0 \\
\hline $\mathbf{5 7 7}$ & 1 & 0 & 1 & 0 & 1 & 0 & 1 & 0 & 1 \\
\hline $\mathbf{5 0 6}$ & 0 & 1 & 0 & 0 & 0 & 1 & 0 & 0 & 0 \\
\hline $\mathbf{4 5 8}$ & 0 & 0 & 0 & 0 & 1 & 0 & 0 & 1 & 1 \\
\hline $\mathbf{3 3 0}$ & 1 & 1 & 1 & 1 & 1 & 1 & 1 & 1 & 1 \\
\hline $\mathbf{3 9 4}$ & 1 & 1 & 1 & 1 & 1 & 1 & 1 & 1 & 1 \\
\hline $\mathbf{4 4 7}$ & 0 & 1 & 0 & 0 & 0 & 1 & 0 & 1 & 0 \\
\hline Total & 6 & 7 & 4 & 3 & 5 & 7 & 4 & 5 & 5 \\
\hline
\end{tabular}


Assiut J. Agric. Sci., (47) No. (4) 2016 (136-155)

Website: http://www.aun.edu.eg/faculty_agriculture/
ISSN: 1110-0486

E-mail:ajas@aun.edu.eg

44B

\begin{tabular}{|c|c|c|c|c|c|c|c|c|c|}
\hline MW & $\begin{array}{c}\text { Abd el- } \\
\text { naby 1 }\end{array}$ & $\begin{array}{c}\text { Abd } \\
\text { elnaby } \\
\mathbf{2}\end{array}$ & $\begin{array}{c}\text { Abd } \\
\text { elnaby } \\
\mathbf{3}\end{array}$ & $\begin{array}{c}\text { El- } \\
\text { masry 1 }\end{array}$ & $\begin{array}{c}\text { Kh. } \\
\text { Ebn } \\
\text { elwald }\end{array}$ & $\begin{array}{c}\text { Abas } \\
\text { gaffer }\end{array}$ & $\begin{array}{c}\text { El- } \\
\text { masry } \\
\mathbf{2}\end{array}$ & Radwan & $\begin{array}{c}\text { Ali } \\
\text { Aamer }\end{array}$ \\
\hline $\mathbf{7 1 1}$ & 0 & 0 & 0 & 1 & 1 & 0 & 1 & 0 & 0 \\
\hline $\mathbf{5 4 0}$ & 1 & 1 & 1 & 0 & 0 & 0 & 1 & 1 & 1 \\
\hline $\mathbf{4 8 3}$ & 1 & 1 & 1 & 1 & 1 & 1 & 1 & 1 & 1 \\
\hline $\mathbf{4 1 8}$ & 1 & 1 & 1 & 1 & 1 & 1 & 1 & 1 & 1 \\
\hline $\mathbf{3 7 1}$ & 1 & 1 & 1 & 1 & 1 & 1 & 1 & 1 & 1 \\
\hline $\mathbf{3 3 0}$ & 1 & 1 & 1 & 1 & 1 & 1 & 1 & 1 & 1 \\
\hline $\mathbf{2 8 6}$ & 1 & 1 & 1 & 1 & 1 & 1 & 1 & 1 & 1 \\
\hline Total & 6 & 6 & 6 & 6 & 6 & 6 & 7 & 6 & 6 \\
\hline
\end{tabular}

HB-08

\begin{tabular}{|c|c|c|c|c|c|c|c|c|c|}
\hline MW & $\begin{array}{c}\text { Abd el- } \\
\text { naby 1 }\end{array}$ & $\begin{array}{c}\text { Abd el- } \\
\text { naby 2 }\end{array}$ & $\begin{array}{c}\text { Abd el- } \\
\text { naby 3 }\end{array}$ & $\begin{array}{c}\text { El-masry } \\
\mathbf{1}\end{array}$ & $\begin{array}{c}\text { Kh. Ebn } \\
\text { elwald }\end{array}$ & $\begin{array}{c}\text { Abas } \\
\text { gaffer }\end{array}$ & $\begin{array}{c}\text { El-masry } \\
\mathbf{2}\end{array}$ & Radwan & $\begin{array}{c}\text { Ali Aa- } \\
\text { mer }\end{array}$ \\
\hline $\mathbf{6 2 2}$ & 0 & 1 & 1 & 1 & 1 & 1 & 1 & 1 & 1 \\
\hline $\mathbf{4 1 4}$ & 1 & 1 & 1 & 1 & 1 & 1 & 1 & 1 & 1 \\
\hline $\mathbf{4 6 2}$ & 0 & 0 & 0 & 0 & 0 & 1 & 1 & 1 & 1 \\
\hline $\mathbf{5 2 3}$ & 0 & 1 & 1 & 1 & 1 & 1 & 1 & 1 & 1 \\
\hline $\mathbf{7 9 3}$ & 0 & 0 & 0 & 0 & 0 & 0 & 1 & 1 & 1 \\
\hline $\mathbf{2 7 3}$ & 1 & 1 & 1 & 1 & 1 & 1 & 1 & 1 & 1 \\
\hline $\mathbf{3 6 3}$ & 1 & 1 & 1 & 1 & 1 & 1 & 1 & 1 & 1 \\
\hline $\mathbf{3 1 4}$ & 0 & 1 & 1 & 1 & 1 & 1 & 1 & 1 & 1 \\
\hline $\mathbf{2 4 8}$ & 0 & 0 & 0 & 0 & 0 & 1 & 1 & 1 & 1 \\
\hline Total & 3 & 6 & 6 & 6 & 6 & 8 & 9 & 9 & 9 \\
\hline
\end{tabular}

HB-12

\begin{tabular}{|c|c|c|c|c|c|c|c|c|c|}
\hline $\mathbf{M W}$ & $\begin{array}{c}\text { Abd } \\
\text { elnaby 1 }\end{array}$ & $\begin{array}{c}\text { Abd } \\
\text { elnaby 2 }\end{array}$ & $\begin{array}{c}\text { Abd } \\
\text { elnaby 3 }\end{array}$ & $\begin{array}{c}\text { El- } \\
\text { masry 1 }\end{array}$ & $\begin{array}{c}\text { Kh. Ebn } \\
\text { elwald }\end{array}$ & $\begin{array}{c}\text { Abas } \\
\text { gaffer }\end{array}$ & $\begin{array}{c}\text { El- } \\
\text { masry 2 }\end{array}$ & Radwan & $\begin{array}{c}\text { Ali Aa- } \\
\text { mer }\end{array}$ \\
\hline $\mathbf{3 4 7}$ & 1 & 1 & 1 & 1 & 1 & 1 & 1 & 1 & 1 \\
\hline $\mathbf{3 8 4}$ & 1 & 1 & 1 & 1 & 1 & 1 & 1 & 1 & 1 \\
\hline $\mathbf{4 5 2}$ & 1 & 1 & 1 & 1 & 1 & 1 & 1 & 1 & 1 \\
\hline $\mathbf{4 8 9}$ & 1 & 1 & 1 & 1 & 1 & 1 & 1 & 0 & 1 \\
\hline $\mathbf{5 5 5}$ & 0 & 1 & 1 & 1 & 1 & 1 & 1 & 1 & 1 \\
\hline $\mathbf{7 6 7}$ & 1 & 0 & 0 & 0 & 0 & 0 & 0 & 0 & 0 \\
\hline $\mathbf{7 2 2}$ & 0 & 0 & 0 & 0 & 0 & 1 & 0 & 0 & 0 \\
\hline $\mathbf{7 0 7}$ & 0 & 1 & 0 & 0 & 0 & 0 & 0 & 0 & 0 \\
\hline $\mathbf{6 3 8}$ & 0 & 0 & 0 & 0 & 1 & 0 & 0 & 0 & 0 \\
\hline $\mathbf{5 1 0}$ & 0 & 1 & 0 & 0 & 0 & 0 & 0 & 0 & 0 \\
\hline $\mathbf{6 1 3}$ & 0 & 0 & 1 & 1 & 0 & 0 & 0 & 0 & 0 \\
\hline $\mathbf{8 1 6}$ & 0 & 0 & 1 & 0 & 0 & 0 & 0 & 0 & 0 \\
\hline $\mathbf{9 6 1}$ & 0 & 0 & 1 & 0 & 0 & 0 & 0 & 0 & 0 \\
\hline $\mathbf{1 1 0 9}$ & 0 & 0 & 1 & 0 & 0 & 0 & 0 & 0 & 0 \\
\hline $\mathbf{3 1 3}$ & 1 & 1 & 1 & 1 & 1 & 1 & 1 & 1 & 1 \\
\hline $\mathbf{2 6 6}$ & 1 & 1 & 1 & 1 & 1 & 1 & 1 & 1 & 1 \\
\hline $\mathbf{2 4 5}$ & 0 & 0 & 0 & 0 & 0 & 1 & 1 & 0 & 1 \\
\hline Total & 7 & 9 & 11 & 8 & 8 & 9 & 8 & 6 & 8 \\
\hline
\end{tabular}




\section{HB-15}

\begin{tabular}{|c|c|c|c|c|c|c|c|c|c|}
\hline $\mathbf{M W}$ & $\begin{array}{c}\text { Abd elnaby } \\
\mathbf{1}\end{array}$ & $\begin{array}{c}\text { Abd elnaby } \\
\mathbf{2}\end{array}$ & $\begin{array}{c}\text { Abd elnaby } \\
\mathbf{3}\end{array}$ & $\begin{array}{c}\text { El-masry } \\
\mathbf{1}\end{array}$ & $\begin{array}{c}\text { Kh. Ebn } \\
\text { elwald }\end{array}$ & $\begin{array}{c}\text { Abas } \\
\text { gaffer }\end{array}$ & $\begin{array}{c}\text { El-masry } \\
\mathbf{2}\end{array}$ & Radwan & Ali Aamer \\
\hline $\mathbf{1 1 1 8}$ & 0 & 0 & 1 & 1 & 0 & 0 & 1 & 1 & 1 \\
\hline $\mathbf{8 8 6}$ & 0 & 0 & 1 & 0 & 0 & 0 & 0 & 0 & 0 \\
\hline $\mathbf{8 1 8}$ & 0 & 0 & 1 & 1 & 0 & 0 & 1 & 1 & 1 \\
\hline $\mathbf{7 0 9}$ & 0 & 0 & 0 & 0 & 0 & 0 & 1 & 1 & 1 \\
\hline $\mathbf{6 9 5}$ & 0 & 0 & 1 & 0 & 0 & 0 & 0 & 0 & 0 \\
\hline $\mathbf{6 1 3}$ & 1 & 1 & 1 & 1 & 0 & 0 & 1 & 1 & 1 \\
\hline $\mathbf{5 4 3}$ & 1 & 1 & 1 & 1 & 1 & 1 & 1 & 1 & 1 \\
\hline $\mathbf{4 3 9}$ & 1 & 1 & 1 & 1 & 1 & 1 & 1 & 1 & 1 \\
\hline $\mathbf{3 5 5}$ & 1 & 1 & 1 & 1 & 1 & 1 & 1 & 1 & 1 \\
\hline $\mathbf{3 1 4}$ & 1 & 1 & 1 & 1 & 1 & 1 & 1 & 1 & 1 \\
\hline $\mathbf{2 7 8}$ & 0 & 0 & 0 & 0 & 0 & 0 & 1 & 1 & 1 \\
\hline Total & 5 & 5 & 9 & 7 & 4 & 4 & 9 & 9 & 9 \\
\hline
\end{tabular}

\section{All primers}

The ISSR analysis products produced by the five primers investigated are shown in Table (10).

All primers reacted with the nine types, producing a unique band pattern for each cultivar. From a total of 297 scorable bands only 19 bands were conserved among all cultivars.

A maximum of 74 fragments were amplified with primer HB-12 and a minimum of 46 fragments were amplified with primers 14-A. Arrangement of primers depending on the number of DNA fragments produced HB-12 > HB-O8 > HB-15 > $44 \mathrm{~B}$ and 14-A. This study showed a considerable amount of genetic variation in the nine date palm strains investigated.

\section{Genetic specific markers:}

Unique DNA fragments with different size detected using different primers in a particular cultivar but not in the others could be used as positive DNA markers. The results showed that the number of specific bands produced by the five primers was 13 ranged in size of (510) bp to (1109) bp. The highest number of specific bands was 8 produced by HB-12 primer while the lowest number was 2 produced by HB-15primer.

The primers detected 6 unique bands with Abd elnaby 3 cultivars, 3 bands with Abd elnaby 1, two with Abd elnaby 2 and one with Khaled ebn elwalid and Abas gaffer.

\section{Similarity Matrix:}

Data of the presence/absence of DNA fragments and pair-wise comparisons between the tested date palm cultivars were used to calculate the genetic similarity (Si) (Table 11).

The highest similarity values was found with Abd elnaby 1 and Abas gaffer $(\mathrm{Si}=1)$ and with Abd elnaby 1 and Abd elnaby $2(\mathrm{Si}=.86)$. This reflects the closest relationship between the two cultivars. Meanwhile, the lowest similarity value was found between El-masry 2 and Ali Aamer $(\mathrm{Si}=0)$. 
Table 11. Similarity index.

\begin{tabular}{|c|c|c|c|c|c|c|c|c|}
\hline & $\begin{array}{c}\text { Abd elnaby } \\
\mathbf{1}\end{array}$ & $\begin{array}{c}\text { Abd elnaby } \\
\mathbf{2}\end{array}$ & $\begin{array}{c}\text { Abd elnaby } \\
\mathbf{3}\end{array}$ & $\begin{array}{c}\text { El- } \\
\text { masr } \\
\mathbf{y} \mathbf{1}\end{array}$ & $\begin{array}{c}\text { Kh. } \\
\text { Ebn el- } \\
\text { wald }\end{array}$ & $\begin{array}{c}\text { Abas gaf- } \\
\text { fer }\end{array}$ & $\begin{array}{c}\text { El- } \\
\text { masry } \\
\mathbf{2}\end{array}$ & Radwan \\
\hline Abd elnaby 2 & 0.86 & & & & & & & \\
\hline Abd elnaby 3 & 0.74 & 0.67 & & & & & & \\
\hline El-masry 1 & 0.74 & 0.37 & 0.37 & & & & & \\
\hline $\begin{array}{c}\text { Kh. Ebn el- } \\
\text { wald }\end{array}$ & 0.73 & 0.52 & 0.52 & 0.32 & & & & \\
\hline Abas gaffer & 1.00 & 0.17 & 0.81 & 0.57 & 0.57 & & & \\
\hline El-masry 2 & 0.85 & 0.63 & 0.52 & 0.35 & 0.49 & 0.56 & & \\
\hline Radwan & 0.85 & 0.68 & 0.68 & 0.54 & 0.67 & 0.61 & 0.24 & \\
\hline Ali Aamer & 0.82 & 0.68 & 0.56 & 0.41 & 0.41 & 0.61 & 0.00 & 0.21 \\
\hline
\end{tabular}

\section{Dendrogram analysis:}

A dendrogram generated by DICE computer package demonstrating the relationship among the nine strains, based on ISSR markers, is shown in Figure (2). Which separated strains into three major groups. The first is divided into two sub groups, the first sub group included Elmasry 2, Ali Aamer and Radwan. The second sub groups divided into two sub sub main group, the first sub sub group included strains Elmasry 1 and Kh. ebn elwalid strains. The second sub sub group included Abd elnaby 3 strain only. The second main group included Abd elnaby 2 and Abs gaffer strains. The third main group included Abd elnaby 1 strain only. The results of ISSR are in harmony with (Adawy, 2004; Soliman, 2006; Hemeid, 2007; Ibrahim, 2008; Abdalla, 2012, Gadalla, 2013).

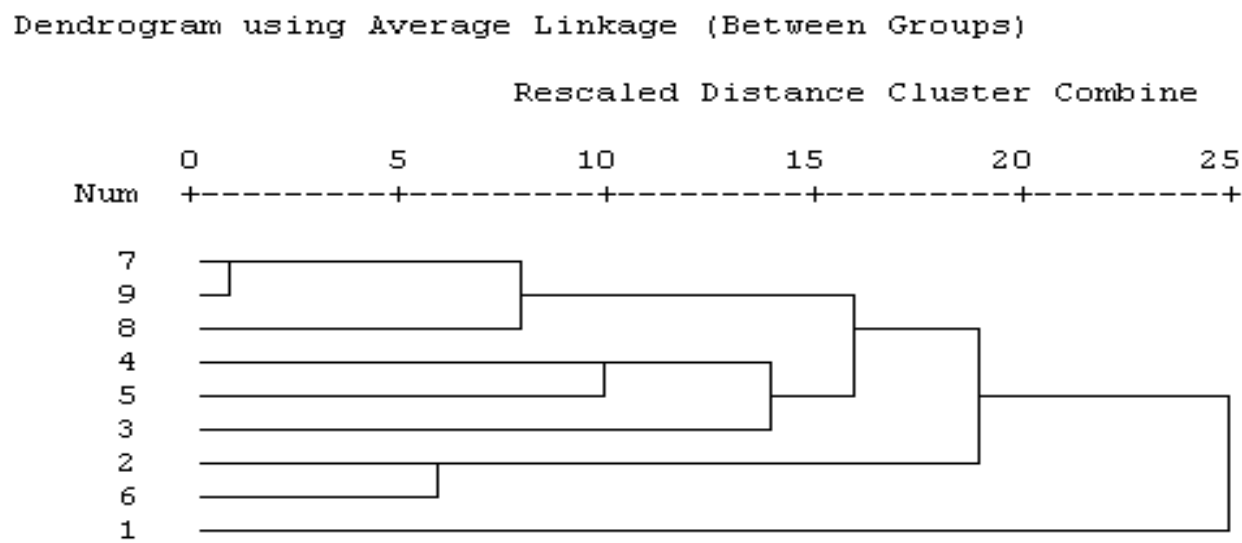

Figure 2: Dendrogram demonstrating the relationship among the nine cultivars based on data recorded from polyoprhism of ISSR markers. 


\section{References}

A.O.A.C. Association of Official Agricultural Chemists (1985). Official Methods of Analysis A.O.A.C. Benjamin Franklin Station, Washington D.C. MSA. pp. 440-512.

Abdalla, A.S. (2002). Evaluation of three date palm seedling types grown at El-Dakhla Oasis New Valley, Egypt. Proc. Minia $1^{\text {st }}$ Conf. for Agric. and Environ. Sci. Minia, Egypt, March 25-28, pp. 17551763.

Abdalla, M.G. (2012). Evaluation of some seeded date palm trees grown under Assiut climatic conditions. M.Sc. Thesis, Fac. Agric., Assiut Univ., Egypt.

Abo Rekab, Z.A.M.; E.G. Gadalla and S.Y. Mohamed (2010). Morphological, physiological and Molecular genetic evaluation of the most important Egyptian dry date palm. Biol. Chem. Environ. Sci., 5(3): 23-47.

Adawy, S.S.; E.H.A. Hussein; D. ElKhishin; M.M. Saker; A.A. Mohamed and H.A. El-Itriby (2004). Genotyping Egyptian date palm cultivars using RAPD, ISSR and AFLP markers and estimation of genetic stability among tissue culture derived plants. Biblioctheca Alexandria Conference Center, Alexandria, Egypt.

Annual Statistical of the Ministry of Agriculture in 2015.

Cregan, B. (1992). Simple sequence repeats DNA length polymorphism, Probe, 2: 18-22.

Dice, L. R., (1945). Measures of the amount of ecologic association between species. Ecology. 26: 297302.

El-Sharabasy, S.F.; El. T. El-Baz; O.H. El-Shiaty and F. Fawzi (2003). Evaluation of nine seedling date palm (Phoenix dactylifera L.) males in pollination of Zaghloul date palm cultivar. Zagazig J. Agric. 30 (4): 1463-1475.

FAO, Food Agriculture and organization (2014). Quarterly Bulletins of Statistics 8 (112) 31. Yearly Book Annu. Air Production, 45: 154155.

Gadalla, E. G. (2013). Selection and evaluation of some superior date palm strains growing in Aswan Governorate. Egypt. J. of Appl. Sci., 28 (8): 454-481.

Hemeid, A.A.; Sanaa A. Riad and T.M. El-Rahman (2007). Molecular characterization of different date palm (Phoenix dactylifera L.) cultivars grown in Siwa Oasis. Egypt. J. Genet. Cytol., 36: 145-162.

Hussein, F.; M.S. El-Khatitany and Y.A. Wally (1979). Date palm growing and date production in the Arab and Islamic World. Ain Shams Press (In Arabic), Egypt.

Ibrahim, R.A. (2008). Physiological studies on some date palm under Assiut conditions. Ph.D. Thesis, Fac. Agric., Assiut Univ., Egypt.

Ismail, B.; I. Hoffar; R. Baalbaki; Y. Mechref and J. Henry (2006). Physico-chemical characteristics and total quality of five date varieties grown in the United Arab Emirates. International J. of Food Sci. and Technology, 41 (8): 919.

Jaradate, A.A. and A. Zaid (2004). Quality traits of date palm fruits in a center of origin and center of diversity. International J. of Food, Agric. and the Environment, 2 (1): 208-217.

Khayyat, M.; E. Tafazoli; S. Eshaghi and S. Rajaee (2007). Effect of nitrogen, boron, potassium and zinc sprays on yield and fruit quality of date palm. American Eurasian J. Agric. \& Environ. Sci., 2 (3): 289296.

Rokba, A.M.; S.A. Seif and A.I. Abou El-Azayem (1990). Biological 
studies on some date palm seedling grown in Fayoum Governorate. J. Agric. Sci. Mansoura Univ. 15 (2): 232-238.

Shabana, H.R. and N.S. Antoun (1980). The determination of leaf area in date palm "Beitroya zur Tropischen Land Wirtschaft and Veterinar Medizin, 18 (4): 345349. (C.F. Hort. Abst. 51: 9012).

Snedecor, G.W. and W.G. Cochran (1980). Statistical methods $7^{\text {th }}$ Ed. The Iowa State Univ. Press. Ames, pp. 365-372.

Soliman, Kh.; R.M. Rizk and S.F. ElSharabasy (2006). Genetic polymorphism of semi-dry date palm
(Phoenix dactylifera L.) cultivars in Egypt. J. Biotechnol., 22: 261273.

Williams, J.G.K.; A.R. Kubelik; K.J. Livak; J.A. Rafalski and S.V. Tingey (1990). DNA polymorphisms amplified by arbitrary primers are useful as genetic markers. Nucleic Acids Res., 18: 6531-6535.

Zehdi, S.L.; H.L. Sakka; A. Rhouma; A. Ould Mohamed Salem; M.L. Marrakchi and M.L. Trifi (2004). Analysis of Tunisian date palm germplasm using simple sequence repeat primers. African J. of Biotech., 3 (4): 215-219. 
تقييم بعض أثجار نخيل البلح الجاف البذرية النامية تحت ظروف أسوان المناخية

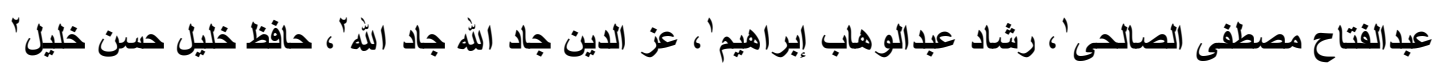

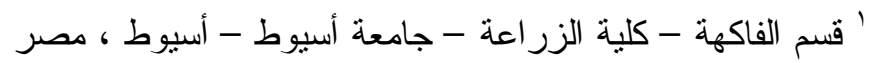

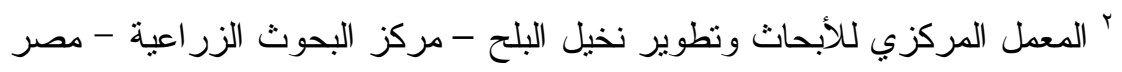

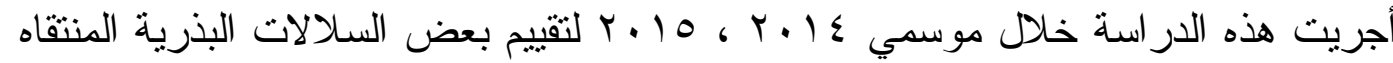

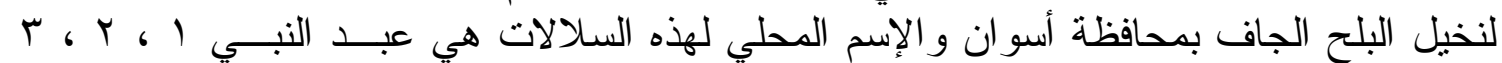

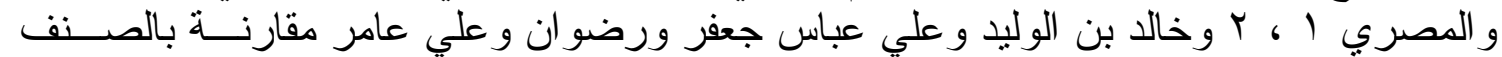

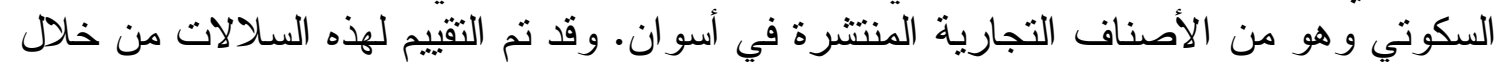
در اسة بعض صفات النمو الخضري ومكونات المحصول وخصائص الثمار الطبيعية و الكيماوية

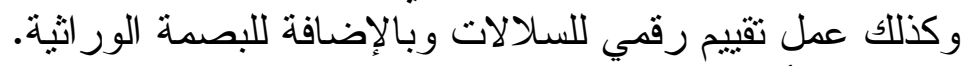

$$
\text { وقد أظهرت النتائج الآتي: }
$$

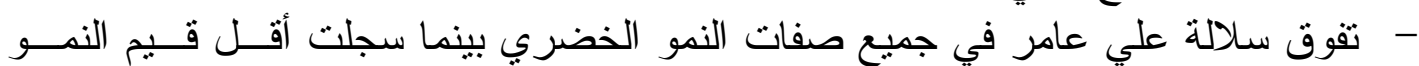
الخضري بنخيل السكوتي مقارنة بالسالالات الأخري.

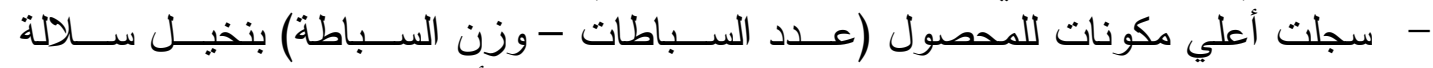

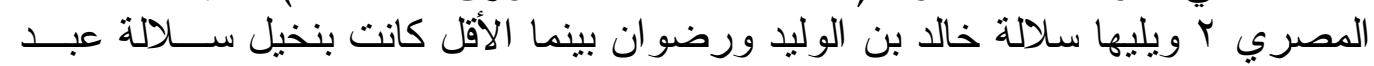

$$
\text { النبي ا. أنمان }
$$

- أعطت سلالة خالد بن الوليد أفضل صفات ثمرية ويليها سلالة المصــري ب و عبــاس جعفر • بينما سجلت أقل قيم الصفات الثمرية بثمار البلح السكوتي.

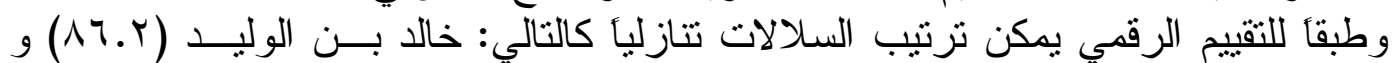

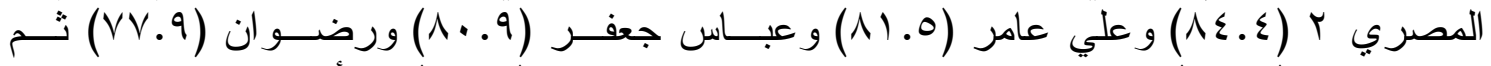

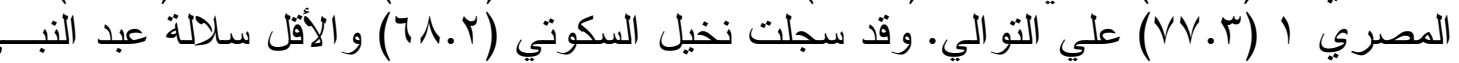

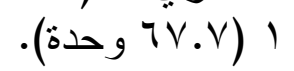
كما أوضحت نتائج ISSR المستخدم لتقدير التشابه الور اثي بين التسع سلالات لنخيل البلح

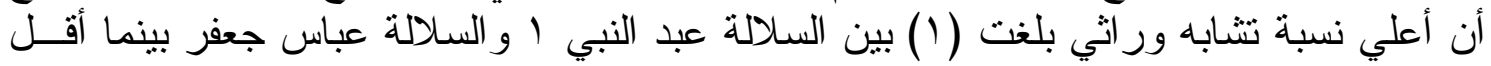

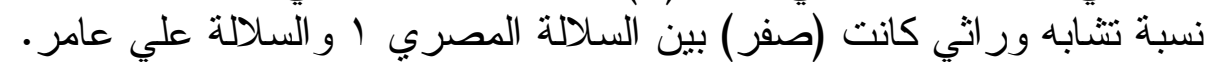

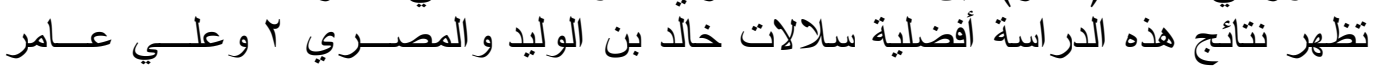

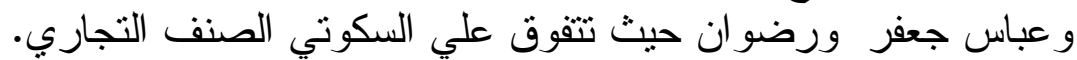

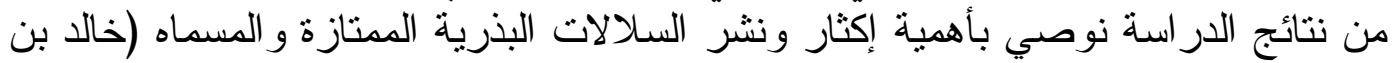

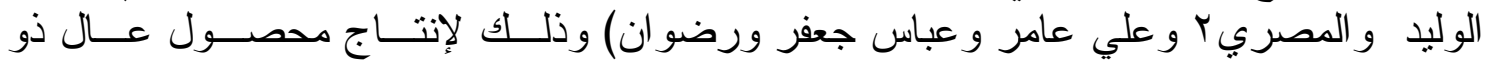
خصائص ثرية جيدة. 